\title{
Mechanical Evaluation of the Effect of Reducing Phosphoric Acid Concentrations and Etching Duration on the Bond Strength of Orthodontic Brackets
}

\author{
Mahmoud Al-Suleiman ${ }^{1 *}$, Feras Baba ${ }^{1}$, Sawan MN $^{2}$ and Ayman Suliman ${ }^{1}$ \\ ${ }^{1}$ Department of Orthodontics, University of Aleppo Dental Faculty, Syria \\ ${ }^{2}$ Department of Orthodontics, University of Damascus Dental Faculty, Syria
}

Received: July 21, 2014; Accepted: August 08, 2014; Published: August 25, 2014

*Corresponding author: Prof. Mahmoud Alsuleiman, Department of Orthodontics, University of Aleppo Dental Faculty, Syria, Tel: 96626540400; Email: alsuleimanm@gmail.com

\begin{abstract}
The bonding of orthodontic brackets was concerned an important subject in orthodontics practice. In past study by using a scanning electron microscope we concluded that the result of enamel treatment with $37 \%$ phosphoric acid concentration was damaging and resulted in destruction of enamel prisms for both studied times $60 \mathrm{sec}$. and $30 \mathrm{sec}$. While $25 \%$ phosphoric acid concentration showed better results than $37 \%$, it removed only the center of prisms. We did not find any substantial difference for various etching times.

The purpose of this study was to evaluate the effect of different phosphoric acid $\left(\mathrm{H}_{3} \mathrm{PO}_{4}\right)$ concentrations and etching duration on the bond strength of orthodontic brackets on enamel surface. To achieve this aim, 48 extracted premolars were used. Two phosphoric acid concentrations were applied (37\% and $25 \%$ ) with two different times (30 sec and $60 \mathrm{sec}$ ). The bond strengths were measured by Testometric M350-machine.

Analysis of the results revealed: Reversal relationship between the strength shear and the concentration of phosphoric acid $(p<0.05)$. The shear bond strength with $25 \%$ phosphoric acid concentration was significantly increased $(p<0.05)$. However, we didn't find significant difference between two etching times $(30 \& 60$ sec) $(p>0.05)$. The shear bond strength with $37 \%$ phosphoric acid concentration was significantly decreased $(p<0.05)$ and decreased more when we delayed the application time $(p<0.05)$. The results of this study suggested that a $25 \%$ phosphoric acid concentration with 60 sec etching duration marked the higher bond strength.
\end{abstract}

Keywords: Shear bond strength; Bonding; Phosphoric acid concentrations; Etching duration

\section{Introduction}

The acid-etched technique had introduced by Bounocore [1]. The pretreating of enamel surface with $37 \%$ phosphoric acid for (30-15) sec caused dissolution of prism cores and prism boundaries only $(5-50) \mu[2,3]$.
Since this initial report, various investigators have evaluated the technique to determine the factors that might affect [2,4-7] on the strength of the mechanical bond including the type of enamel conditioner, acid concentration, length of etching time, and using another materials to obtain the optimal conditions for bonding and decreasing the damage of enamel [5-12]. The conventional adhesive for bonding orthodontic brackets to enamel had many different affecting agents such as, age of patient, the fluoride outer layer of enamel [10-14], depth of dissolution [8-16].

Past studies used phosphoric acid with many concentrations $(5,15,37) \%$ with different application times $(15,30,60) \mathrm{sec}$ [8] and concluded that the acid concentration can be reduced significantly without a significant increase in the failure of bonded attachments. A study by Carstensen [6], study showed [17] that reducing the acid concentration from $37 \%$ to $15 \% \mathrm{H}_{3} \mathrm{PO}_{4}$ and applying it for 60 seconds had no significant difference. SEM showed that the 15 sec duration for phosphoric acid concentration $37 \%$ was better than other durations and any increase in the duration could lead to increase the damage in the prism. While many studies $[12,13]$ demonstrated that the optimal length of time for applying phosphoric acid 37\% to the orthodontic bonding area of mandibular premolars was 30 seconds. The calculated etch depths [15] ranged from $27.1 \mu \mathrm{m}$ by etching with $37 \% \mathrm{H}_{3} \mathrm{PO}_{4}$ for 60 seconds to $3.5 \mu \mathrm{m}$ by etching with $5 \% \mathrm{H}_{3} \mathrm{PO}_{4}$ for 15 seconds [15].

Hu et al. [16] found low-quality evidence that was insufficient to conclude whether or not there is a difference in bond failure rate between Self Etching Primers (SEPs) and conventional etching systems when bonding fixed orthodontic appliances regarding the superiority of different etching materials, concentrations or etching times.

Taking into account that the application [8] of solutions greater than $27 \% \mathrm{H}_{3} \mathrm{PO}_{4}$ to enamel results in the formation of monocalcium phosphate monohydrate, whereas with weaker 
$\mathrm{H}_{3} \mathrm{PO}_{4}$ solutions the main reaction product is dicalcium phosphate dihydrate. The monocalcium phosphate monohydrate is more soluble than dicalcium phosphate dihydrate and will be more readily washed from the enamel surface after etching.

With the introduction of the acid-etched convention and the duration applied we see that concentration $[9,15,16]$ and timing $[8,13,17]$ is still under search in spite of existence another material using to bonding such as: nitric acid [12], sandblasting [18] or laser [19] and all of them did not give good bond strength or safety on the penetration of enamel surface.

So the purpose of this study was to

- $\quad$ evaluate the effect of different phosphoric acid $\left(\mathrm{H}_{3} \mathrm{PO}_{4}\right)$ concentrations (25-37)\% and etching duration (30-60) sec on the bond strength of orthodontic brackets on enamel surface and determined the optimal conditions compare the results with SEM analysis results

\section{Materials and Methods}

\section{Criteria for tooth selection for SEM analysis}

Forty freshly extracted human bicuspid were collected and stored in a solution of $10 \%$ formol. The criteria for tooth selection included intact buccal enamel, not subjected to any pretreatment chemical agents such as phosphoric acid, hydrogen peroxide, no cracks due to the presence of the extraction forceps, and no caries. The teeth were cleaned and polished with pumice for 20 seconds.

\section{Preparation of teeth for SEM}

The etched specimens were prepared for scanning electron microscopy (SEM) by sputter coating with gold to a thickness of $10 \mathrm{~nm}$; viewing was carried out with SEM operated at $10 \mathrm{kV}$.

\section{Method of evaluation under SEM}

- All specimens were scanned from the buccal area, as the middle third of the crown was the area where bonding of orthodontic brackets performed. Microphotographs were taken at a magnification of 100x, 400x, 1000x, 2000x, 4000x, 5000x, 6000x, and 7000x and every photo of the micrograph was evaluated according to the following objectives: Elimination of the prisms center only

- Elimination of inter prism material

- Destruction of the prism structures

- Width and the diameter of the prisms

\section{Criteria for tooth selection for strength testing}

Forty-eight freshly extracted human bicuspid were collected and stored in a solution of $10 \%$ formol. The criteria for tooth selection included intact buccal enamel, not subjected to any pretreatment chemical agents such as: phosphoric acid, hydrogen peroxide, no cracks due to the presence of the extraction forceps, and no caries. The teeth were cleaned and polished with pumice for 20 seconds.
The teeth were embedded in acrylic in phenolic rings. A mounting jig was used to align the facial surface of the tooth in order for it to be perpendicular with the bottom of the mold. Each tooth was oriented with the testing device as a guide, so its labial surface was parallel to the force during the shear strength test.

\section{Etching procedures}

The specimens of SEM study had divided to four groups: two groups etched with phosphoric acid concentration 25\% (for 30$60) \mathrm{sec}$, and another two groups etched with phosphoric acid concentration $37 \%$ (for 30-60) sec.

Group 1: (10 bicuspid) Phosphoric acid 25\%/30 sec

Group 2: (10 bicuspid) Phosphoric acid 25\%/60 sec

Group 3: (10 bicuspid) Phosphoric acid 37\%/30 sec

Group 4: (10 bicuspid) Phosphoric acid 37\%/60 sec

The specimens of strength testing study had divided to four groups. Two groups etched with phosphoric acid concentration $25 \%$ for (30-60) sec, and another two groups etched with phosphoric acid concentration $37 \%$ for $(30-60)$ sec.

Group 1: (12 bicuspid) Phosphoric acid 25\%/30 sec

Group 2: (12 bicuspid) Phosphoric acid 25\%/60 sec

Group 3: (12 bicuspid) Phosphoric acid 37\%/30 sec

Group 4: (12 bicuspid) Phosphoric acid 37\%/60 sec

\section{Bonding procedure}

Stainless steel metal brackets (Forestadent Company) were used. And the brackets were bonded to the teeth according to the protocol using (system-RMO/mono-lok 2 bonding) to secure adhesion of the brackets. The mean area of the bracket base surface was $12.4 \mathrm{~mm}^{2}$.

\section{Debond strength testing}

Testometric M350 was used to test shear bond strength. The specimen that was mounted in its acrylic block of the machine was secured to the lower grip of the machine (fixed head). To maintain a consistent debonding force, a custom-made blade was fixed in the upper grip (movable head) connected to the load cell. The blade was positioned in such a way that it touched the bracket.

A cross-head speed of $2 \mathrm{~mm} /$ minute was used. The computer recorded the debonding force of the bracket in Newton. The bond strength was calculated in Megapascals. The surface area of the bracket was $12.4 \mathrm{~mm}^{2}$, as given by the manufacturer.

\section{Results}

I. Exam under the SEM

1) Phosphoric acid 25\%/30 sec group showed good etching surface and ideal concentration because prism material was not damaged and the width of penetration was $3-4 \mu$ as $6000 \mathrm{x}$.

2) Phosphoric acid 25\%/60 sec group showed elimination 
of the prisms center while the prism material has no damage; the depth of penetration was about (10-5) $\mu$ as 4000x.

3) Phosphoric acid 37\%/30 sec group showed that the penetration was not optimal, Because of the elimination of the prism and inter prism material, and the prism had no regular shape under magnification of 7000x.

4) Phosphoric acid 37\%/60 sec group showed absolute damage in the prisms that remained after applying the phosphoric acid and weak penetration.

II. The mean and standard deviations of the shear bond strengths were subjected to Student's T-test (Table 1).

III. Comparison between the groups to determine the ideal conditions for bonding (Table 2).

1) Phosphoric acid 37\%/30 sec - Phosphoric acid 37\%/60 sec : $p=0.017$

2) Phosphoric acid 25\%/30 sec - Phosphoric acid 25\%/60 sec $: p=0.465$

3) Phosphoric acid 37\%/30 sec - Phosphoric acid 25\%/30 sec $: p=0.021$

4) Phosphoric acid 37\%/60 sec - Phosphoric acid 25\%/60 sec $: p=0.004$

IV. Correlation between (1) strength shear and concentration (2) strength shear

1) Inverse relationship exists between the strength shear and the concentration of phosphoric acid, $p=0.022$.

2) No significant correlation between the strength shear and the duration of phosphoric acid application, $p=0.504$.

\section{Discussion}

Bonding orthodontics brackets to enamel is still problematic [16,20-24]. Acid etching of enamel is recommended with many bonding systems to improve the delivery of orthodontic treatment $[2,16,22,23]$.

Past studies into enamel etching had used a variety of materials and methods, which had made inter-study comparison difficult. This investigation controlled the study sample by using mandibular premolars from 10 to 18 year old white adolescents with a lifelong history of residence in nonfluoridated areas.

Table 1:

\begin{tabular}{|c|c|c|c|}
\hline Shear Grouping & Mean & N & Std. Deviation \\
\hline Phosphoric Acid 25\%/30 sec & 15.4667 & 12 & 4.49734 \\
\hline $\begin{array}{c}\text { Phosphoric Acid } \\
25 \% / 60 \text { sec }\end{array}$ & 16.9075 & 12 & 4.98450 \\
\hline $\begin{array}{c}\text { Phosphoric Acid } \\
\text { 37\%/30 Sec }\end{array}$ & 14.9667 & 12 & 3.50203 \\
\hline Phosphoric Acid 37\%/60 sec & 11.8633 & 12 & 2.27799 \\
\hline Total & 14.8010 & 48 & 4.25322 \\
\hline
\end{tabular}

Several factors might influence bond strength including: The type of enamel conditioner, acid concentration [5-10,12$15]$, and length of etching time $[2,8,9]$. The evaluation of shear bond strength in vitro has been used till date, to study bonding procedures of orthodontics brackets [16,22,25]. Greenlaw [26] showed that minimum strength for bonding was influenced with position of bracket, occlusion force and orthodontic force, the value was however not determined; while Reynolds [27] showed that bond strength was at least 7-6 MPa.

Traditionally, phosphoric acid concentration 37\% was applied for a duration of $30 \mathrm{sec}[4,5,12-20]$ and Legler [8] showed that if the concentration of $\mathrm{H}_{3} \mathrm{PO}_{4}$ solution that was applied to the enamel was greater than $27 \%$, it resulted in the formation of monocalcium phosphate monohydrate; whereas with weaker $\mathrm{H}_{3} \mathrm{PO}_{4}$ solutions the main reaction product was dicalcium phosphate dihydrate. The monocalcium phosphate monohydrate is more soluble than dicalcium phosphate dihydrate, as Carstensen [6] showed that bond strength was greater, when the concentration of acid increased because penetration of enamel was increased. Wang and Chau TZ [7-14] found that the penetration increased when the etching time increased, so our results under SEM demonstrated that concentration 37\% caused elimination of the inter prism material and destruction of the prism structures according to duration applied, while concentration $25 \%$ caused elimination of the prisms center only, without damage of the inter prism material and the same time strength shear for concentration $25 \%$ was larger than concentration $37 \%$ for $30-60$ sec (Table 2). These findings are in agreement with those of Cehreli [10] and Bishara et al. [5], who determined that phosphoric acid caused damage to the prism at a concentration of $37 \%$; it was therefore not ideally suitable for bonding the bracket.

We found that there was no significant difference when concentration 25\% was applied for 30 and 60 sec (Table 2), and it was in agreement with specimens under SEM, which only showed the elimination of the prisms center without destruction of the prism material and the diameter of penetration was about [5-10] $\mu$ with concentration $25 \%$ for $60 \mathrm{sec}$; while the etching for $30 \mathrm{sec}$ had same characters but the diameter of penetration was about $3 \mu$. We also found that the application of concentration $37 \%$ for 30 and 60 sec resulted in a significant difference. The strength shear decreased to $11.86 \pm 2.27$ Mpa when applied for $60 \mathrm{sec}$, in agreement with most studies (Table 2). Also, SEM analysis revealed that there was damaging in enamel surface and wracking in the prism for concentration 37\% for $60 \mathrm{sec}$. These results lead to the inference that application of phosphoric acid in a concentration of $25 \%$ for $60 \mathrm{sec}$ was better than the concentration of $37 \%$ and strength shear was larger than 5.04 $\pm 1.58 \mathrm{Mpa}$. Correlation between the shear bond strength and the concentration of the phosphoric acid had significant deference (Table 3) and there was a reversal relation between the shear bond strength and the concentration of phosphoric acid for the two duration that mentioned. Which mean that the shear strength increased with concentration $25 \%$ for the two durations, and decreased with $37 \%$ concentration for the two durations that agree with studies of Cehreli ZC [10] and Bishara 
Table 2: Independent Samples Test.

\begin{tabular}{|c|c|c|c|c|c|c|}
\hline Levene's Test for Equality of Variances & & & $\begin{array}{l}\text { t-test for Equality } \\
\text { of Means }\end{array}$ & & & \\
\hline & Shear & $\begin{array}{c}\text { Sig. } \\
\text { (2-Tailed) }\end{array}$ & Mean Difference & $\begin{array}{l}\text { Std. Error } \\
\text { Difference }\end{array}$ & $\begin{array}{l}95 \% \text { Confidence } \\
\text { Interval of the } \\
\text { Distance }\end{array}$ & \\
\hline & & & & & Lower & Upper \\
\hline \multirow[t]{3}{*}{$\begin{array}{c}\text { Phosphoric acid } 37 \% / 30 \mathrm{sec} \text { - Phosphoric } \\
\text { acid } 37 \% / 60 \mathrm{sec}\end{array}$} & $\begin{array}{l}\text { Equal variances } \\
\text { assumed }\end{array}$ & $0.017^{*}$ & 3.1033 & 1.20601 & 0.60223 & 5.60444 \\
\hline & $\begin{array}{l}\text { Equal variances not } \\
\text { assumed }\end{array}$ & 0.019 & 3.1033 & 1.20601 & 0.57818 & 5.6849 \\
\hline & $\begin{array}{l}\text { Equal variances } \\
\text { assumed }\end{array}$ & 0.465 & -1.4408 & 1.93802 & -5.460 & 2.5783 \\
\hline $\begin{array}{l}\text { Phosphoric acid } 25 \% / 30 \mathrm{sec} \text { - Phosphoric } \\
\text { acid } 25 \% / 60 \mathrm{sec}\end{array}$ & $\begin{array}{l}\text { Equal variances not } \\
\text { assumed }\end{array}$ & 0.465 & -1.4408 & 1.93802 & -5.462 & 2.58083 \\
\hline \multirow[t]{2}{*}{$\begin{array}{l}\text { Phosphoric acid } 37 \% / 30 \mathrm{sec} \text { - Phosphoric } \\
\text { acid } 25 \% / 30 \mathrm{sec}\end{array}$} & $\begin{array}{l}\text { Equal variances } \\
\text { assumed }\end{array}$ & $0.021^{*}$ & 3.6033 & 1.45531 & 0.58520 & 6.62147 \\
\hline & $\begin{array}{l}\text { Equal variances not } \\
\text { assumed }\end{array}$ & 0.025 & 3.6033 & 1.45531 & 0.52275 & 6.68392 \\
\hline \multirow[t]{2}{*}{$\begin{array}{l}\text { Phosphoric acid } 37 \% / 60 \mathrm{sec} \text { - Phosphoric } \\
\text { acid } 25 \% / 60 \mathrm{sec}\end{array}$} & $\begin{array}{l}\text { Equal variances } \\
\text { assumed }\end{array}$ & $0.004^{* *}$ & 5.044 & 1.58205 & 1.7632 & 8.3251 \\
\hline & $\begin{array}{l}\text { Equal variances not } \\
\text { assumed }\end{array}$ & 0.006 & 5.0442 & 1.58205 & 1.6798 & 8.4085 \\
\hline
\end{tabular}

Table 3: Correlations.

\begin{tabular}{|c|c|c|c|c|}
\hline & & Shear strength & Concentration & Timing \\
\hline \multirow{3}{*}{ Shear strength } & Pearson Correlation & 1 & $-0.329 *$ & -0.099 \\
\cline { 2 - 5 } & Sig. (2-tailed) & & 0.022 & 0.504 \\
\cline { 2 - 5 } & $\mathrm{N}$ & 48 & 48 & 48 \\
\hline
\end{tabular}

${ }^{*}$ Correlation is significant at the 0.05 level (2-tailed).

SE et al. [5] which mentioned that concentration 37\% did not give the optimal etching.

Correlation between the strength shear and the application time had no significant impact this confirms that the acid concentration plays an essential role on bonding forces.

We found that lower concentration of acid provides better and significant strength shear, as opposed to the findigs of Legler LR [8] who concluded that the duration of the acid application affects the strength shear.

\section{Conclusion}

1) Using phosphoric acid concentration $25 \%$ is important for direct bonding of brackets.

2) Phosphoric acid concentration $37 \%$ was not found to be the optimal concentration.

3) When using phosphoric acid concentration 37\%, eyching time should not be increased over $30 \mathrm{sec}$, because the application time of $60 \mathrm{sec}$, causes wrack of the prism and decreases the strength shear.

4) Phosphoric acid concentration 25\%, is the best for application time of both 30 and $60 \mathrm{sec}$.

\section{References}

1. BUONOCORE MG. A simple method of increasing the adhesion of acrylic filling materials to enamel surfaces. J Dent Res. 1955; 34(6): 849-53.

2. Lopes GC, Thys DG, Klaus P, Oliveira GM, Widmer N. Enamel acid etching: a review. Compend Contin Educ Dent. 2007; 28(1): 18-24.

3. Grabare TM, Swain N. Current principles and techniques. Missouri: CV Mosby; 1985.

4. Osorio R, Toledano M, Garcia-Godoy F. Bracket bonding with 15- or 60- second etching and adhesive remaining on enamel after deboning. Angle Orthod. 1999; 69(1): 45-8.

5. Bishara SE, Gordan VV, VonWald L, Olson ME. Effect of an acidic primer on shear bond strength of orthodontic brackets. Am J Orthod Dentofacial Orthop. 1998; 114(3): 243-7.

6. Carstensen W. Effects of reduced phosphoric acid concentration on shear bond strength. Am. J. Orthodontics. 1995; 108(2): 274-277.

7. Wang W, Chau TZ. Direct strength with varions etching times. Am J Orthodontics Dentofacial Orthop. 1991; 100(1): 72-9.

8. Legler LR, Retief H. Effects of phosphoric acid concentration and etching duration on shear strength of bonding resin to enamel. Am J Orthodontics Dentofacial Orthop. 1989; 96(6): 485-92.

9. Carstensen W. The effects of different phosphoric acid concentrations 
on surface enamel. Angle Orthod. 1992; 62(1): 51-8.

10. Cehreli ZC, Altay N. Effects of a nonrinse conditioner and 17\% ethylenediaminetetraacetic acid on the etch pattern of intact human permanent enamel. Angle Orthod. 2000; 70(1): 22-7.

11. Watari F. In-Situ etching observation of human teeth in acid agent by atomic force microscopy. J Electron Microsc (Tokyo). 1999; 48(5): $537-44$.

12. Gardner A, Hobson R. Variations in acid-etch patterns with differen acids and etch times. Am J Orthod Dentofacial Orthop. 2001; 120(1) 64-7.

13. Johnston CD, Hussey DL, Burden DJ. Effect of etch duration on the microstructure of molar enamel, An in vitro study. Am J Orthod Dentofacial Orthop. 1996; 109(5): 531-4.

14. Chow LC, Brown WE. Phosphoric acid conditioning of teeth for pit and fissure sealants. J Dent Res. 1973; 52(5): 1158.

15. Legler LR, Retief DH, Bradley EL. Effects of phosphoric acid concentration and etch duration on enamel depth of etch: An in vitro study. Am J Orthod Dentofacial Orthop. 1990; 98(2): 154-60.

16. Hu H, Li C, Li F, Chen J, Sun J, Zou S, et al. Enamel etching for bonding fixed orthodontic braces. Cochrane Database Syst Rev. 2013; 11 CD005516. doi: 10.1002/14651858.CD005516.pub2.

17. Sadowsky PL, Retief DH, Cox PR, Hernández-Orsini R, Rape WG, Bradley EL. Effects of etchant concentration and duration on the retention of orthodontic brackets: An in vivo study. Am J Orthod Dentofacial Orthop. 1990; 98(5): 417-21.

18. Olsen ME, Bishara SE, Boyer DB, Jakobsen JR. Effect of varying etching times on the bond strength of ceramic brackets. Am J Orthod Dentofacial Orthop. 1996; 109(4): 403-9.

19. Van Waveren Hogervorst WL, Feilzer AJ, Prahl-Andersen B. The air- abrasion technique versus the conventional acid-etching technique: $\mathrm{A}$ quantification of surface enamel loss and a comparison of shear bond strength. Am J Orthod Dentofacial Orthop. 2000; 117(1): 20-6.

20. Talbot TQ, Blankenau RJ, Zobitz ME, Weaver AL, Lohse CM, Rebellato J. Effect of argon laser irradiation on shear bond strength of orthodontic brackets: An in vitro study. Am J Orthod Dentofacial Orthop. 2000; 118(3): 274-9.

21. Topcuoglu T, Oksayan R, Topcuoglu S, Coskun ME, Isman NE. Effect of Er: YAG laser pulse duration on shear bond strength of metal brackets bonded to a porcelain surface. Photomed Laser Surg. 2013; 31(6): 240-6. doi: 10.1089/pho.2012.3463.

22. Rao KS, Reddy TP, Yugandhar G, Kumar BS, Reddy SN, Babu DA. Comparison of shear bond strength of resin reinforced chemical cure glass ionomer, conventional chemical cure glass ionomer and chemical cure composite resin in direct bonding systems: an in vitro study. J Contemp Dent Pract. 2013; 14(1): 21-5.

23. Gardner A, Hobson R. Variations in acid-etch patterns with different acids and etch times. Am J Orthod Dentofacial Orthop. 2001; 120(1): 64-7.

24. Alsulaimani FF. Effect of Lactic Acid Etching on Bonding Effectiveness of Orthodontic Bracket after Water Storage. ISRN Dent. 2014 ; doi: $10.1155 / 2014 / 719608$.

25. Chalipa J, Akhondi MS, Arab S, Kharrazifard MJ, Ahmadyar M, Evaluation of shear bond strength of orthodontic brackets bonded with nano-filled composites. J Dent (Tehran). 2013; 10(5): 461-5.

26. Greenlaw R1, Way DC, Galil KA. An in vitro evaluation of a visible lightcured resin as an alternative to conventional resin bonding systems. Am J Orthod Dentofacial Orthop. 1989; 96(3): 214-20.

27. Reynolds IR, von Fraunhofer JA. Direct bonding of orthodontic brackets-a comparative study of adhesives. Br J Orthod. 1976; 3(3): 143-6. 